\title{
EDUCAÇÃO PARA A ARTE NA AMAZÔNIA: CAMINHOS COMO VIAS DE ESCOLHAS
}

\section{Vânia Leal Machado Curadora Educacional Arte Pará}

\section{Resumo}

Este trabalho se propõe a fazer um estudo que envolvem professores e alunos e incitam para a construção de interações entre museus, instituição Cultural e Escola. Investiga a mediação cultural entre arte e público nas suas múltiplas relações integrada aos segmentos do projeto curatorial do Arte Pará. Investiga o processo de ensino-aprendizagem da escola com foco nas práticas de experiências externas como caminhos de construção sobre um discurso de educação para arte na Amazônia.

\section{Palavras-chave:}

Mediação Cultural; Arte Pará; Amazônia.

A educação tem importância para a Fundação Romulo Maiorana ${ }^{1}$ desde a sua criação em 1981. O Projeto Pedagógico do Arte Pará ${ }^{2}$ atinge um patamar significativo com a implantação da curadoria educacional integrada aos segmentos do projeto curatorial abrindo assim, caminhos de construção sobre um discurso de educação para arte na Amazônia. As questões acerca das condições sociais e culturais relativas a professores e alunos que incitam a construção de interações entre museu, instituição cultural e escola, nos últimos doze anos, têm sido um dos pontos de atenção acerca da minha investigação para os caminhos de construção do conhecimento das ações educativas nos espaços da arte em Belém.

Partindo desse campo de formação de educadores como mediadores culturais e de professores da rede estadual e municipal, analiso alguns prognósticos que incidem sobre os processos de ensino e de aprendizagem em arte, para circunscrever a análise sobre tais interações, que nos dá um perfil sobre as competências socioculturais e artísticoestéticas de estudantes universitários, professores
Abstract

This work proposes to make a study involving teachers and students and encourage the construction of interactions between museums, Cultural institution and School. It investigates the cultural mediation between art and the public in its multiple relations integrated into the curatorial project segments of Arte Pará. It investigates the teaching-learning process of the school focusing on the practices of external experiences as construction paths on a discourse of education for art in the Amazon.

Keywords:

Art and Music; Baroque Art; Renaissance Art.

do ensino fundamental e médio, crianças e jovens participantes de exposições de arte.

Assim, busco verificar como se dá a inserção nos espaços culturais e na cidade de Belém, com o propósito de estabelecer processos de inclusão e desenvolvimento humano, além de uma conexão sobre o ensino de arte pautado em referências, a partir do diálogo entre a arte e a vida contemporânea, com o objetivo de travar relações com a produção artística atual.

Acreditamos que diante do processo de formação estamos dando um passo significativo no que se refere à qualidade, à rede de desdobramentos de suas ações, e ao fortalecimento de relações que se constroem nas proposições educacionais.

O projeto educativo curatorial se justifica por razões nas quais não mensuramos grau de importância: os espaços expositivos como o campo de ação do compromisso social e cultural em suas diversas proposições, pela forma como a mostra vai colocar os visitantes em contato com maneiras de pensar e viver no mundo. 


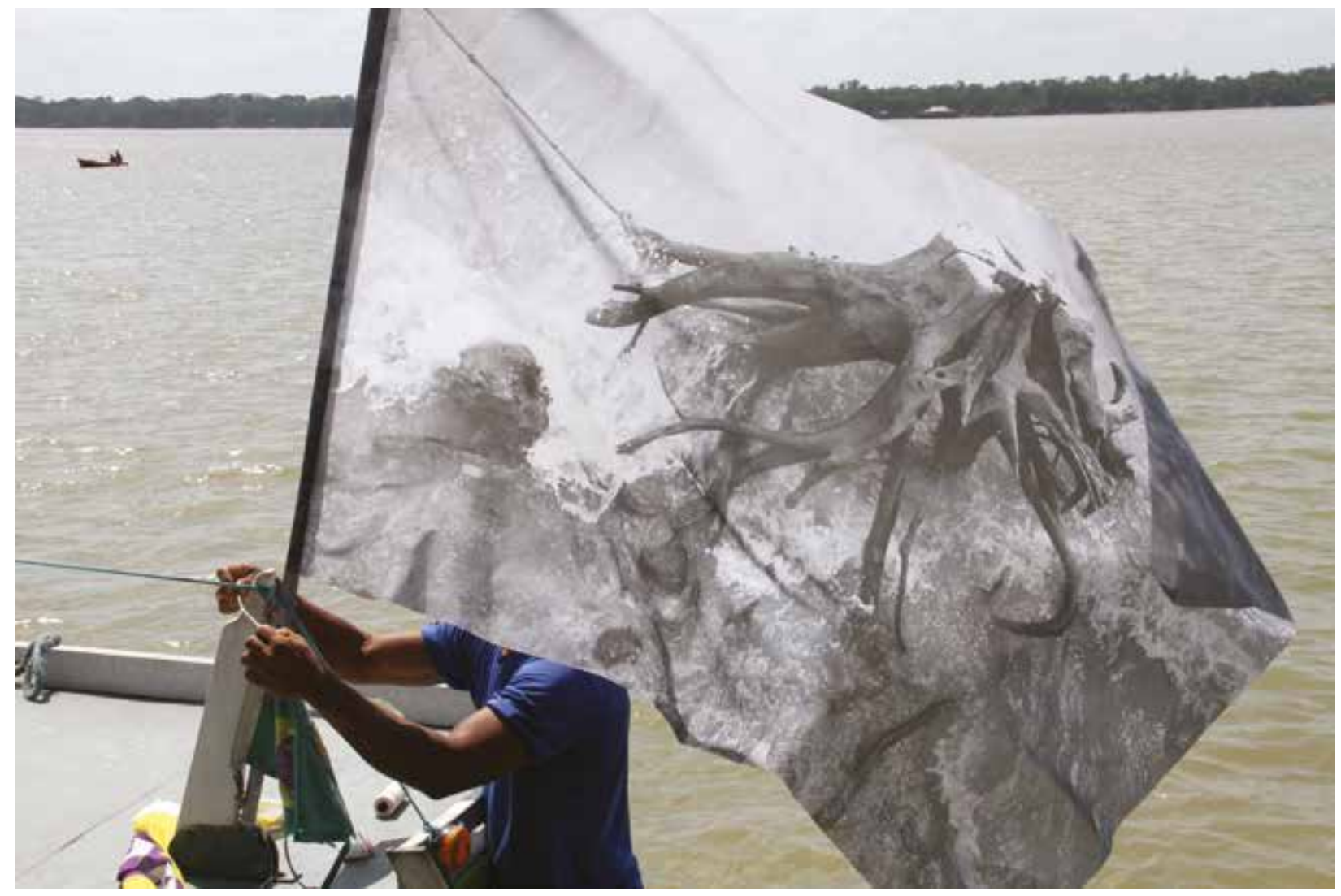

Figura 2 - Árvore. Partida. Combu. Paula Sampaio.

meu campo de observação se dá justamente na qualidade dessa experiência e o quanto ainda precisamos avançar no exercício da cidadania plena que compele o acesso aos bens culturais.

Em se tratando de arte contemporânea especificamente Anne Cauquelin assume uma postura radical e chama atenção que, no universo da arte, o passado foi ontem, pois o que reconhecemos como arte verdadeira é a arte moderna. Afirma: "Sem dúvida, é essa arte moderna que nos impede de ver a arte contemporânea tal como é. Próxima demais, ela desempenha o papel do 'novo', e nós temos a propensão de querer nela incluir à força as manifestações atuais" (CAUQUELIN, 2005, p.19).

A reflexão da autora nos remete à questão que muitas pessoas ainda não entraram no domínio das transformações que aconteceram no campo da arte no século XX e pensam a arte conforme padrões tradicionais, de séculos anteriores. Isso dificulta o contato com as produções da atualidade, cria como ela diz, "uma cortina de fumaça nos olhos que embaça e impede de ver a arte atual". De fato, grande parte do público que frequenta exposições no Arte Pará tende a destinar mais atenção às informações das obras do que às próprias obras e são levadas para o espaço por curiosidade.

Dessa forma, mais do que garantir o acesso aos bens e serviços culturais, estamos com o foco no estímulo e na proposição do diálogo entre a produção artística e o grande público, por meio de processos educativos. Entendemos que não basta apenas proporcionar o contato do público com arte. É necessário mediar esse contato, educando os sentidos, fomentando a fruição das obras, a leitura das obras de arte contemporânea, estimulando o apreciador a parar, observar, sentir, refletir, interagir, produzir, formular hipóteses, questionamentos e perceber novas estéticas e novas formas de aproximações na arte.

Tem sido este o empenho do Salão Arte Pará nestes últimos anos, por meio de parcerias com escolas, instituições de pesquisa, IES, ONG'S e Secretaria de Educação. O resultado disto é que desde $2008,70 \%$ do público do salão foi 



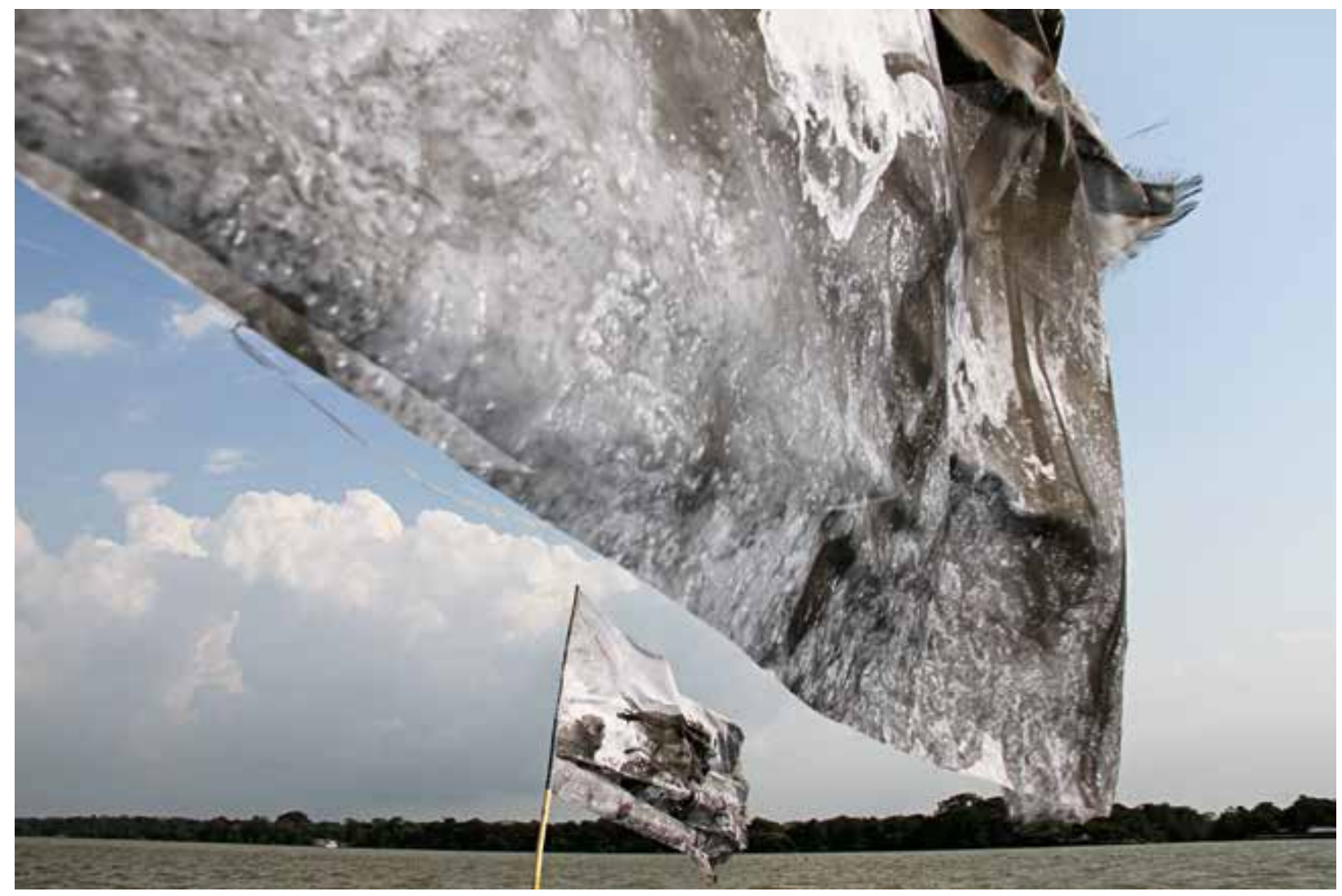

Figura 4 - Árvore. Libertação ao vento. Combu. Paula Sampaio.

O artista na Amazônia é um depositário da herança cultural e de valores. Também testemunha cotidianamente uma experiência dramática e perversa. Como conciliar desenvolvimento, respeito às populações tradicionais (índios, ribeirinhos, quilombolas e outros grupos), ecologia, sustentabilidade, progresso, conhecimento, justiça social e geopolítica? [...] Alguns caminhos inscrevem a produção da região amazônica no plano internacional. Seus artistas têm uma intimidade com o valor simbólico da Amazônia, a diversidade cultural de tempos assincrônicos, a floresta e a biodiversidade, enfim, muito mais (HERKENHOFF, 2010, p. 90).

Estes ambientes de contradições cotidianas descritas por Herkenhoff formam uma ampla rede de pesquisa para os artistas, curadores, educadores contemporâneos locais que atravessam no olhar a superação das fronteiras legais.

Ressaltamos que na urbana Belém amazônica convivem sedimentações identitárias que formam na dinâmica cotidiana de populações ribeirinhas a convivência com o rio e ao mesmo tempo, em um espaço tão curto, uma população cuja converge contraditoriamente para um ambiente extremamente complexo onde o cotidiano simples ao mesmo tempo, contrapõe-se drasticamente ao ritmo acelerado construído no centro da cidade.

Portanto, o trabalho do educador deve ser conduzido por atitudes dialógicas capazes de romper $\mathrm{o}$ isolacionismo presente na sociedade contemporânea. Paulo Freire adverte sobre as ações no âmbito da educação e da cultura, alertando-nos para a necessidade de atitudes dialógicas nos processos educacionais e culturais.

Dialógica é a atitude que estabelece uma relação diferente entre subjetividades e tem como pressuposto básico a audição das vozes da alteridade. Em sua essência, coexistem três propriedades formadoras que the fornecem, em conjunto, a existência: a dialógica interior (o saber se sentir, se ouvir, se observar); a dialógica exterior (o saber sentir, ouvir, observar o outro) e a dialógica de troca radical (realizada na fronteira entre as duas primeiras e que produz o significado dessa atitude).

Canevacci diz que "a alteridade se torna não em um jogo de interações, mas o pânico desejoso que 


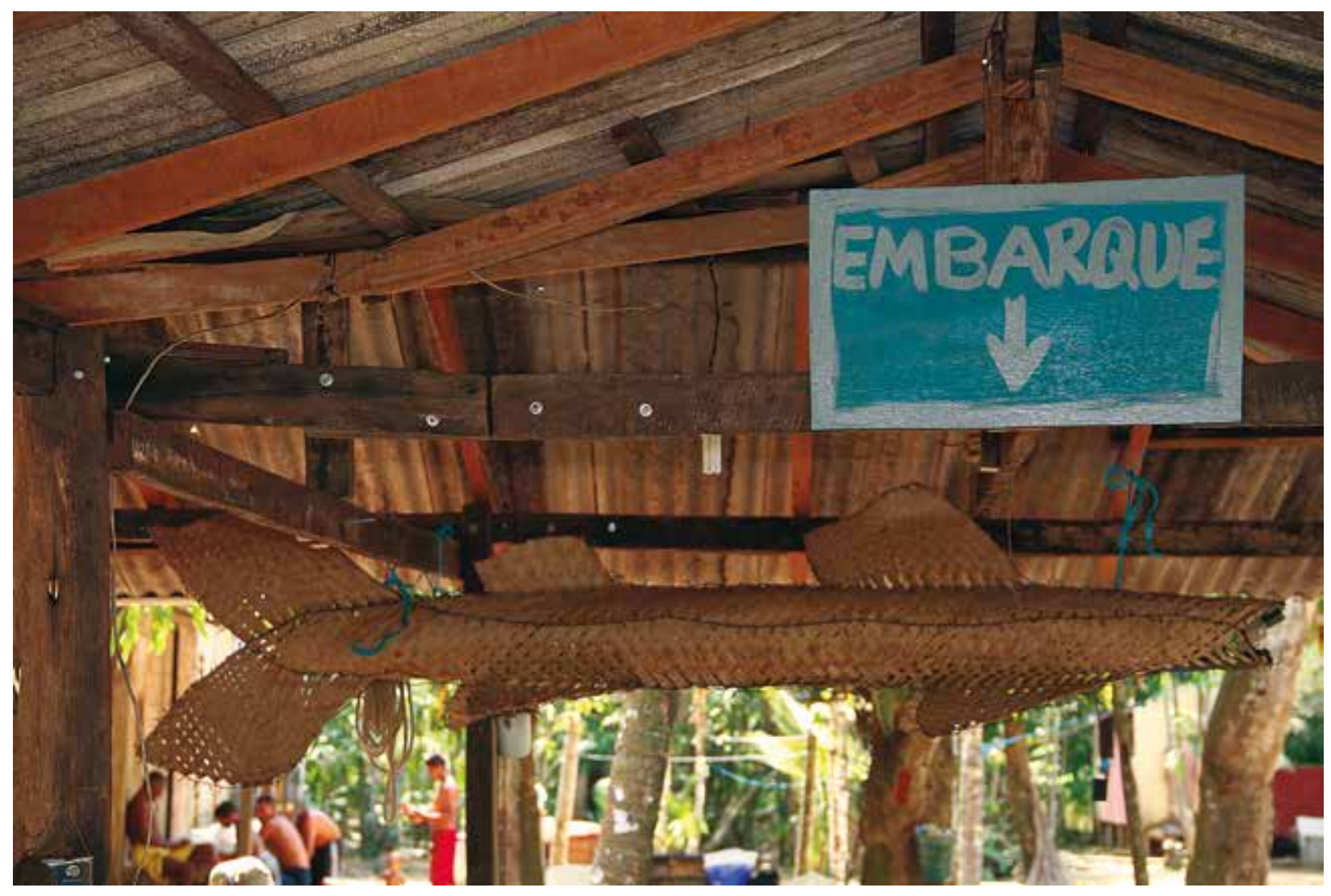

Figura 6 - Árvore. Porto de chegada. Combu. Paula Sampaio.

2012

O caboclo ribeirinho do Combu, da llha, observa a "cidade grande". Verifico nessas teias da modernidade, a natureza com os recursos naturais, com o rio, restaurantes, energia elétrica, turistas, e um fluxo dinâmico de barcos que circulam no rio que forjam novas relações com o ambiente.

Expandir o Arte Pará para a Ilha do Combu foi uma proposição do Curador Paulo Herkenhoff que desde o ano de 2005 expandiu o espaço expositivo para além das salas convencionais do "salão", ocupando as instituições que formam o sistema de arte do Pará, e a própria cidade como, por exemplo, o Complexo Ver-O-Peso, o Mercado de Carne, suscita uma discussão a partir de inúmeras vertentes de ordem artística, cultural, social ou filosófica e que não implica comodidade ou prazer, e sim ambientes que demandam uma interpretação, um esforço aplicativo, uma vontade de estabelecer uma relação.

Não é sem intenção que rompe com as hierarquias artísticas e mistura em um mesmo espaço, convidados e artistas selecionados. As obras estão agregadas não por distinção de prêmios ou pelo reconhecimento do artista no circuito nacional de arte, mas por familiaridades conceituais, por propostas semelhantes ou opostas. Tais decisões são fruto não somente de um conhecimento sobre arte contemporânea, mas também da visão de alguém que tem uma história e um compromisso, desde os anos 1980, com a arte realizada no Pará.

No projeto Arte Pará assume a curadoria por mais de uma década o que impulsiona artistas, curadores e educadores que circulam entre Belém e a cena global.

É nesse contexto que o Arte Pará através da proposição do curador reuniu quatro artistas que se deslocam em um fluxo que permite a expansão das relações estabelecidas em uma dinâmica cultural múltipla, formada por vários pontos de contato no mundo.

Assim, Paula Sampaio, Alexandre Sequeira, Jorane Castro e Thiago Castanho no dia 20 de novembro, numa terça-feira a partir das $18 \mathrm{h00}$, na quadra do Adilson (ADRISON) reuniram a comunidade do Combu e entorno da llha e convidados de Belém 


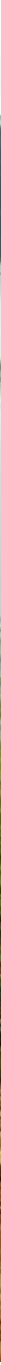

Figura 7 - Árvore. Libertação onde nasceu. Tucuruí. Paula Sampaio.

2013

para à exposição "Tem Arte Pará no Combu" com o objetivo de celebrar a arte no outro lado do rio.

O horário de partida do barco foi as $17 \mathrm{~h} 00$ com saída programada do Porto Beira Rio.

Ao entrarmos no barco a fotógrafa Paula Sampaio, artista homenageada do $31^{\circ}$ Arte Pará convidanos ao Embarque, projeto criado pelo pensamento de seguir variados percursos pelos quais acompanhamos a artista nos espaços expositivos do Arte Pará e nas muitas rotas criadas por ela. A rota agora seria segui-la num pô pô pô que é um nome dado em alusão onomatopéica ao ruído que fazem aos pequenos barcos a motor que aqui navegam. Paula seguia hasteando ao vento a Fotoinstalação-Árvore para ser libertada mais adiante e de longe podíamos observar a artista numa imersão simbiótica com o vasto rio que trazia consigo o barulho da embarcação seguida de uma trilha sonora produzida pela artista que tocava no barco onde estávamos.

O início foi a batida de um sino seguido pelas músicas que compassavam com o barco grande e o pô pô pô que seguia na nossa frente e por vezes desviava para os lados, mas, a rota se cumpria e nos prendia num tempo que nos desnorteava para dentro e fora orquestrando o grafo, a escrita da artista ali sozinha a esmo nas ondas da maré. Imaginei seus embarques por outras rotas da Amazônia, sejam em sua moto, caminhão, barcos e outros meios, afinal, ela atravessou a Transamazônica ao longo de vinte anos com sua câmera fotográfica.

A imagem impressa de um tronco de árvore que ela fotografou no "Lago do Esquecimento", nome que traz a edição de um vídeo para a primeira etapa do projeto de documentação fotográfica sobre o lago de Tucuruí, segundo maior lago artificial do Brasil no Pará, em que a artista deparou-se com um cemitério de árvores e um refúgio para as pessoas que não foram indenizadas e moram no topo das ilhas em torno de Tucuruí, nos coloca diante de um desafio no Arte Pará: O que fazemos diante de tanta incongruência na Amazônia? Esse lago precisou morrer para gerar energia? 0 fato é que junto com ele foram-se vidas e tudo o que foi perdido para a sua formação: áreas indígenas, cidades e inúmeras espécies animais e vegetais. 
Ouvindo-a falar para os mediadores ficou esse registro: "Há $30^{a}$ anos e nada mudou, mas temos que nos rebelar de algum jeito para provocar as discussões nem que sejam umas fotinhas".

Paula naquele cair da tarde nos fez sair das expectativas habituais, nos colocou em situação de vertigem, beirou a dúvida como um convite necessário para a reflexão. Quando o barco ancorou na Ilha, Paula já tinha libertado o "tronco amarrado às margens do lago no cemitério das árvores", impresso nas bandeiras. Agora, simbolicamente, o tronco está livre naquele rio. Através da arte é possível libertar os seres.

Quando pisamos na llha fomos direto para a quadra do Adrisom para ver a exposição fotográfica de Alexandre Sequeira com a série "Meu Mundo Teu".

Nesta série o artista promoveu o conhecimento de dois adolescentes por cartas e fotografias nas quais Tayana Wanzeler, moradora do bairro do Guamá na cidade de Belém e Jefferson Oliveira, morador da ilha do Combú descrevem em detalhes suas vidas através da troca de cartas e imagens realizadas através da experimentação de registros fotográficos com câmeras artesanais de um e dois orifícios além de câmeras convencionais com dupla exposição, resultando em experimentações fotográficas diversas com imagens sobrepostas dos dois mundos: do bairro do Guamá e da Ilha do Combu e da proposição de Alexandre que coloca Tayana e Jefferson como co-autores das imagens reveladas.

As imagens propostas e conduzidas por Sequeira resultam na construção de narrativas entrelaçadas dos dois jovens através da interatividade e relações afetivas que se estabelecem com seus lugares através de elementos simbólicos que animam esse convívio da percepção, capazes de transmitir a dimensão do acontecido.

Essa articulação nem sempre é fácil e requer sutileza e sensibilidade, características peculiares em Alexandre que valoriza o trabalho e a vida das pessoas de onde compõe uma narrativa precisa sobre os caminhos percorridos e as relações que todo viajante estabelece, pois o artista é um andarilho.

Quando estávamos montando a exposição na quadra, D. Aldelina a Sra. Raimunda Nascimento, e Sra. Maria de Fátima e Sra. Patrícia acompanhavam atentamente e ficavam horas olhando as imagens, se reconheciam na fusão das imagens dos dois mundos.

Foi um momento ímpar vê-las observar a exposição com um olhar desprovido de qualquer conceito já pronto da arte, parecia que aquele momento confirmava o objetivo do trabalho de Alexandre na sua forma final que é a de uma história para contar convertendo-se em possibilidades poéticas. A Sra. Raimunda conhecida como "Mundica", avó da família, comentou ao observar uma imagem que registrava a cozinha de sua casa que já havia sido demolida: "O professor Alexandre trouxe nossa casa de volta".

A câmera fotográfica e Alexandre tornam-se neste trajeto, agentes e sujeitos na realidade da Ilha do Combu. O processo dialogado reflete a câmara participativa que integra no cotidiano dos sujeitos a presença do artista como construtor da realidade. A fotografia age como parte indissociável da experiência humana.

O encontro com o outro se mistura com a ética do trabalho que é um pensamento no fotográfico como uma filosofia de vida, afinal, para ele não existe ser humano superior, há sempre uma integração com a natureza.

A noite caia na llha e era grande o movimento dos barcos que chegavam das comunidades próximas. Era a hora do cinema e Jorane Castro nossa cineasta iria fazer o lançamento oficial do filme Ribeirinhos do Asfalto que após percorrer mais de 30 festivais nacionais e internacionais e conquistar dois prêmios em Gramado, iria exibir o filme para a comunidade na qual ele foi inspirado.

Filmado em locais tradicionais de Belém, como Ananindeua, Marituba, Ilha do Combu o e o mercado popular Ver O Peso que mostra de forma sutil a presença dos personagens/sujeitos pela interação, de familiaridade com o contexto do filme e o contexto da llha que mostram a vida acontecendo diante das câmeras que nos levam a penetrar nos momentos da vida cotidiana e situações corriqueiras. Jorane capta essa essência na Amazônia ao trazer para a reflexão, a vida das pessoas e suas relações com os outros e nos fazer dela participar.

A cultura amazônica expressa no filme através da jovem Deisy (Ana Letícia) que gostaria de morar na grande Belém, mas mora na ilha do 
Combu, do outro lado do rio, isolada da cidade que costuma contemplar a distância, não está sendo considerada algo anterior e que é preciso fazer o filme mostrar. 0 cinema no Combu a céu aberto criou um espaço de realização do filme e um ambiente também privilegiado para a reflexão antropológica, pois é pensado como o lugar do encontro, com o espaço em que "observadores" e "observados" não estão separados, se ligam, se juntam, se aliam, pois a observação é recíproca e a troca estabelecida sobre o qual recai o foco da paisagem interna dos personagens.

Ao final da sessão de cinema a celebração foi por conta dos Chefs Thiago e Felipe Castanho da cozinha paraense, que se firmam como representantes da gastronomia nacional e juntamente com as cozinheiras da llha, criaram um cardápio com os ingredientes amazônicos.

Assim, artistas convidados, professores, patrocinadores Arte Pará, moradores da llha e arredores, equipe da Fundação Romulo Maiorana degustaram mingau de banana da terra com leite de coco, vatapá com cuscuz de farinha d'água e, para sobremesa, bolo de macaxeira com calda de maracujá e mousse de chocolate do Combu.

A ação na llha do Combu provocou uma verdadeira interação entre todos que estavam ali presentes. Suscitou uma percepção de deslocamento, desafiou a rotina dos sentidos a qual nos alimentou de toda sorte de coisas e depois nos libertou para exercitar a imaginação, alargando as fronteiras da criação de uma maneira livre e intuitiva.

A arte aconteceu na ilha e pelos caminhos percorridos no rio e na cidade. O curador Paulo Herkenhoff ao dirigir essa ação alinhou os olhares dos quatro artistas e convictamente todos se sentiram a vontade para contar sua história com a mesma paixão do idealizador. Nós fomos felizes em nossa travessia com um desejo em comum de, através da arte fazer da llha do Combu um lugar de encontro e confronto, um lugar que nos colocou para refletir.

Tudo isso pode significar um passo adiante para direcionar a aprendizagem nos espaços da arte, entendendo que é necessário fazê-lo sem manipular, conforme elucidam Paulo Freire e Sérgio Guimarães (1987:19):
[...] o esforço da leitura da realidade através da codificação que representa um pedaço da realidade, era uma leitura manipuladora, dirigida. Ora, dirigida sim, pois não há educação sem intencionalidade, sem diretividade. Manipuladora nunca, [...] mas defender uma posição com que se sonha, antes mesmo de chegar ao educando, é absolutamente legítimo.

E complemento: em nossa proposição não existem respostas precisas, uma vez que os caminhos são diversos, induzindo-nos a pensar: Onde começo? Onde paro? Qual o fim? Qual o desvio? Qual a reta? Este fato nos fala acerca de uma relação do presente, passado e futuro das aprendizagens do público participante, e cria zonas de ações em condições que não estão prontas.

$\mathrm{Na}$ recepção estabelece-se um aqui e agora, mas certamente as bases da arte-educação na contemporaneidade estão presentes em seu campo de incertezas, permitindo múltiplas propostas de ensino com múltiplas linguagens. A arte muda e o público também. A dúvida é inaugurada e promove o conhecimento, e nos assegura uma das incumbências da arte: fazernos pensar, em constante estado de atenção. Cabe a mim e ao outro as vias de escolhas. 


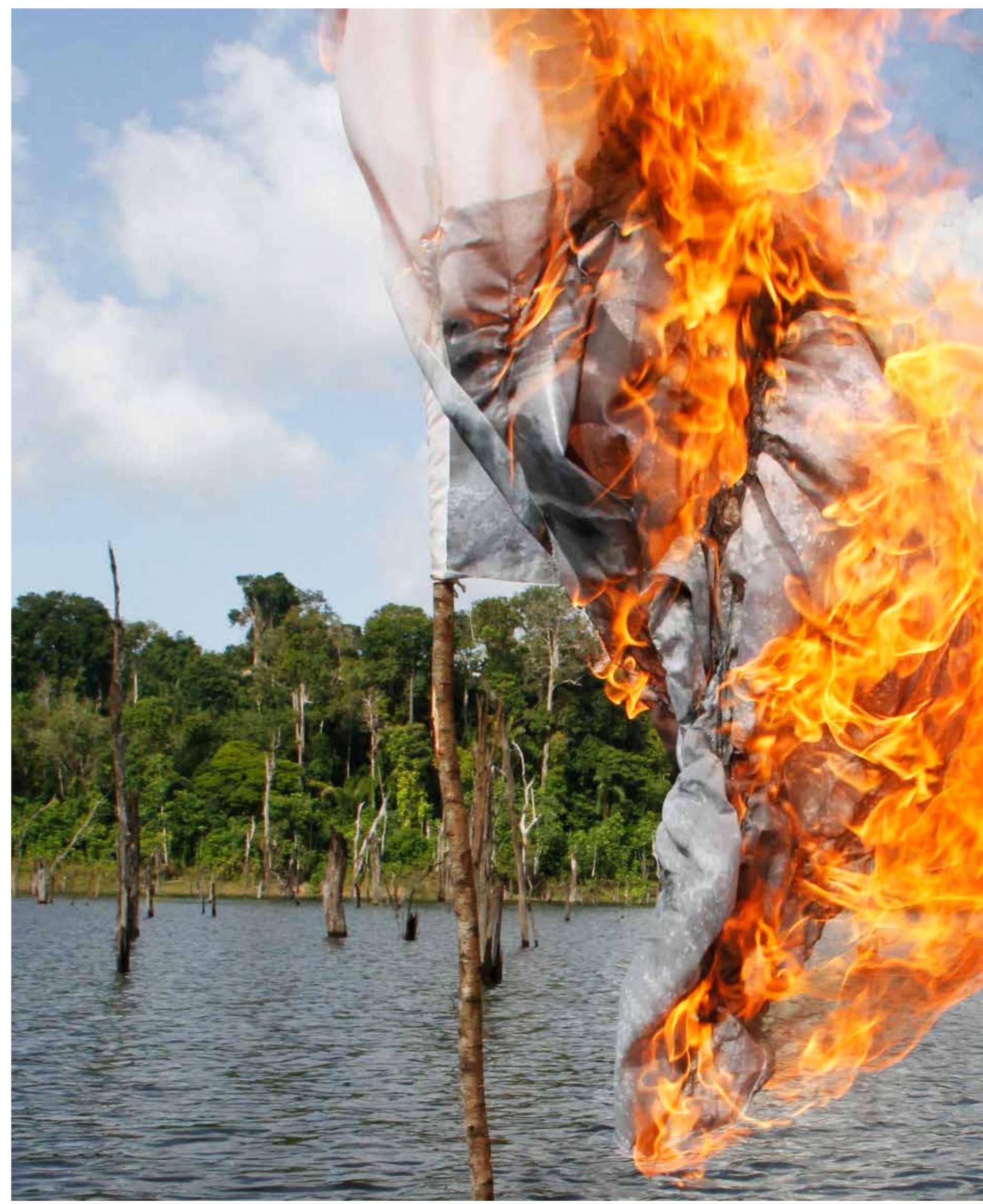




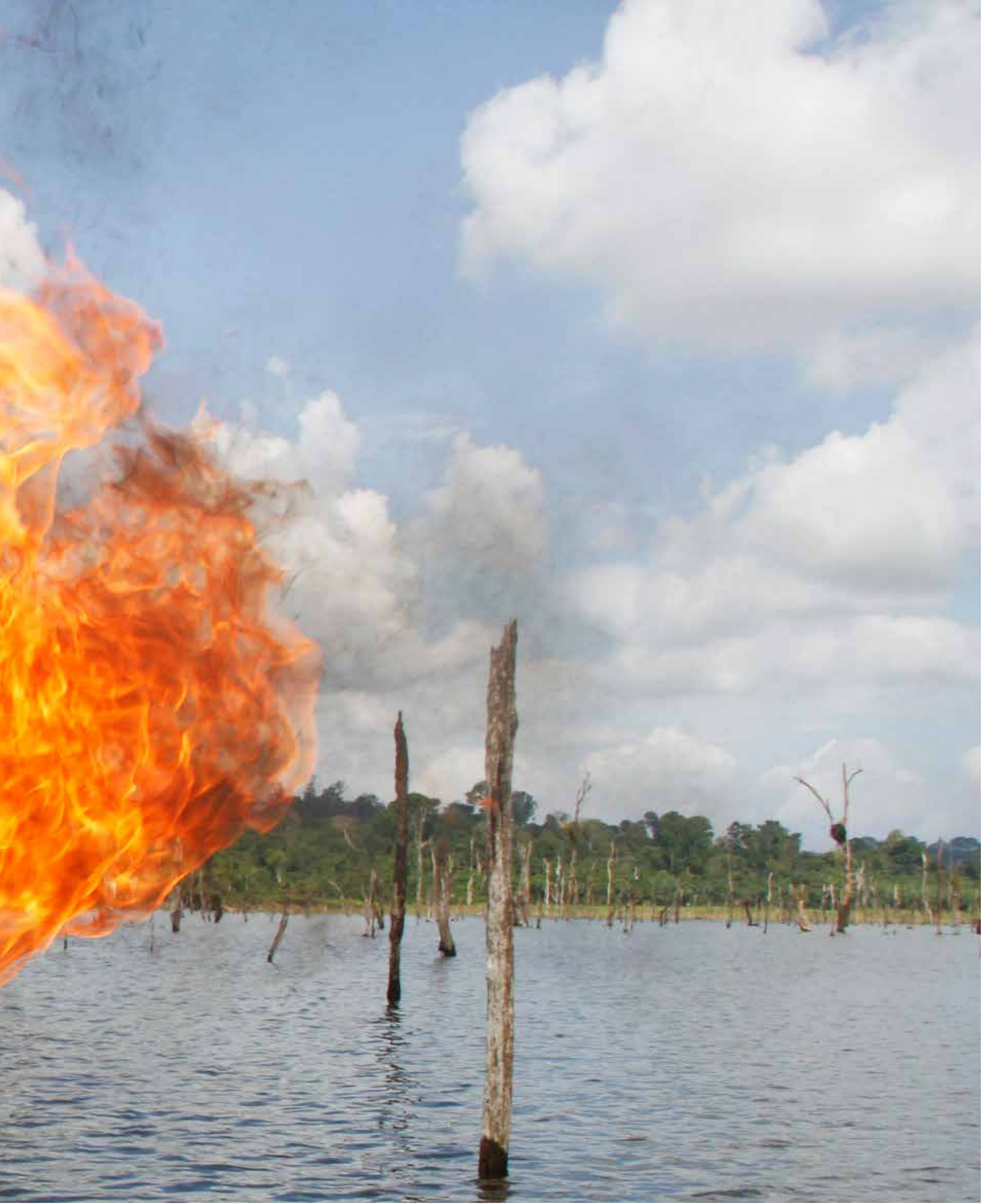

Figura 8 - Árvore. Libertação fogo em Tucuruí. Paula Sampaio. 2013 


\section{NOTAS}

01. Fundada em 1981, a Fundação Romulo Maiorana atua no fomento à produção artística da região Norte. É uma instituição sem fins lucrativos, com atuação maior no campo cultural, sendo um dos mais importantes veículos do terceiro setor. Ao longo de sua história assumiu como missão a realização do sonho do jornalista que the empresta o nome e a idealizou. Não resta dúvida que através da atuação, a instituição ganha destaque no cenário nacional. 0 que faz e o que pensa, é resultado do meio em que atua.

02. O Projeto Arte Pará teve sua origem no início dos anos 1980, motivado por um desejo visionário do jornalista Romulo Maiorana de estimular a produção artística local, desejo esse que irá consolidar um dos projetos mais longevos no cenário nacional, constituindo-se em um dos mais significativos projetos de fomento, acesso e difusão artística no país. O Projeto Arte Pará que começou estimulando a produção artística local, incentivando e viabilizando oportunidades a artistas que hoje detém significativa carreira nacional e internacional, por meio de premiações e do fluxo de críticos e curadores, assa a ser um dos mais importantes projetos educativos pela arte do norte do país, integrando saberes, instituições de ensino, fomentando a participação de estudantes na construção do conhecimento e viabilizando acesso a arte a diversas camadas sociais, realizando ações inclusivas.

\section{REFERÊNCIAS}

MINISTÉRIO DA CULTURA. Diálogos culturais. Disponível em http://www.leidepatrocinio. com.br/incentivo_cultural/aplicativos/ Diagn\%C3\%B3stico_Lei_Rouanet.pdf Acesso em 22 dez. 2012.

BARBOSA. Ana Mae Tavares Bastos. A imagem no ensino da Arte: anos oitenta e novos tempos. $2^{a}$ ed. São Paulo: Perspectiva, 1994.

CANCLINI, Nestor Garcia. As culturas híbridas em tempos de globalização. In: Culturas híbridas: estratégias para entrar e sair da modernidade. São Paulo: EDUSP, 2003.

CANEVACCI, Massimo. Sincretismos: uma exploração das hibridações culturais. São Paulo: Studio Nobel, 1996, 102p.

CATTANI, Icleia Borsa. (org.). Mestiçagens na arte contemporânea. Porto Alegre. Editora da UFRGS, 2007.

CAUQUELIN, Anne. Arte Contemporânea: uma introdução. São Paulo: Martins, 2005.

FREIRE, Paulo. Ação cultural para a liberdade e outros escritos. 7 ed. Rio de Janeiro: Paz e Terra, 1984, 149p.

FREIRE, Paulo \& GUIMARÃES, Sérgio. Aprendendo com a própria história. Rio de Janeiro: Paz e Terra, 1987.

MANESCHY, Orlando. Consultoria / Paulo Herkenhoff. Amazônia, A Arte - Rio de Janeiro: Imago, 2010. Catálogo de arte.

\section{SOBRE A AUTORA}

Vânia Leal Machado é graduada em Artes Plásticas, Especialista em História da Arte, Mestre em Comunicação, Linguagem e Cultura. Coordena a Curadoria Educacional do Projeto Arte Pará, sendo responsável pela Organização do Catálogo anual do Salão e do Encarte Especial Arte Pará no Jornal O Liberal. Atua na área de curadoria e pesquisa em Artes, tendo participado de júris de seleção e premiação e organizações de salões como o 9) Salão de Arte Contemporânea SESC Amapá em 2013, Salão UNAMA de Pequenos Formatos, da Curadoria da individual de Flavya Mutran, Odair Mindelo e Elciclei Araújo no Edital do Banco da Amazônia, e do mapeamento da região norte no Projeto Rumos Itaú Cultural de Artes Visuais, Edição de 2011/2012/2013. 